\title{
The patterns of breast-feeding and their effect on the time of resumption of menses
}

\author{
Lukman Hakim Tarigan
}

\begin{abstract}
Abstrak
Persentasi ibu yang menyusui secara eksklusif pada empat bulan pertama setelah persalinan adalah $50 \%$, dan kurang dari $15 \%$ yang meneruskan sampai dengan 6 bulan. Rata-rata lama menyusui secara eksklusif adalah 3,3 bulan. Median waktu mendapatkan haid setelah persalinan adalah 186 hari (CI: 177-195). Median waktu mendapatkan haid berhubungan secara bermakna dengan lama menyusui secara eksklusif dan juga dengan rata-rata frekuensi menyusui. Hubungan tersebut berbanding lurus. Median waktu mendapatkan haid pada ibu menyusui secara eksklusif sampai dengan tiba bulan dan yang menyusui 4 bulan atau lebih masingmasing adalah: 149 (CI: 121-177) hari dan 199 (CI: 186-212) hari. Pada responden yang menyusui sampai dengan 6 kali perhari median waktu mendapatkan haid adalah 125 hari (CI: 90-160), sementara yang menyusui 6 kali atau lebih per hari adalah 191 hari (CI: 181-201). (Med J Indones 2002; 11: 106-19)
\end{abstract}

\begin{abstract}
The percentage of mother who had fullexclusive breast-feeding for four months after birth are 50\%, and only less than $15 \%$ continued fullexclusive breast-feeding for up to the first six months after birth. The mean duration of fullexclusive breast-feeding is 3.3 months. The median time of the resumption of menses in this study is 186 days (CI: 177-195 days). The median time of resumption of menses significantly associated with both the mean duration of fullexclusive breast-feeding and the average suckling frequency. The longer the mean duration of fulVexclusive breast-feeding and the more the average of suckling frequency, the longer the median time of resumption of menses. The median time of resumption of menses in respondent who practiced fullexclusive breast-feeding up to three and more than three months are 149 (CI: 121-177) and 199 (CI: 186-212) days, respectively. And in the mothers who breast fed their infant for up to six times and more than 6 times per day the median time of resumption of menses are 125 (CI: 90-160) and 191 (CI: 181-201) days, respectively. (Med J Indones 2002; 11: 106-19)
\end{abstract}

Keywords: breastfeeding, lactational amenorrhoea, resumption of menses

The effectiveness of using breast-feeding as an individual contraceptive or child spacing method (known as the lactational amenorrhoea method-LAM) and the main factors that correlate to the time of the resumption of menses are still controversial. Several studies reported different figures: some of them were optimistic about the child spacing effect of breastfeeding and thus used the LAM as a part of their contraceptive program, while others were still looking for more evidence.

At the international conference in Bellagio in 1988 , leading researchers in the areas of lactational infertility reached a consensus that the maximum birth

Department of Epidemiology, Faculty of Public Health, University of Indonesia, Depok, Indonesia fulfilled, breast-feeding provides more than $98 \%$ protection from pregnancy in the first six months. ${ }^{1,2}$

Further research revealed that the contraceptive effect of lactational amenorrhoea (LA) not only occured in women who fully breast-fed but also in women who partially breast-fed, irrespective of the supplements that were introduced into the baby's diets. In practice, fewer than $25 \%$ of mothers fully breast-fed for 6 months. $^{3}$ The pregnancy rates reported during LA tanged from 0.4 to $6 \%$ in the first 6 months. ${ }^{3,4,5}$

From the researches' findings, it is clear that the LA can achieve a greater protection against pregnancy than that afforded by other modern methods of contraception. However, Kennedy and Visness ${ }^{5}$ concluded that the probability of pregnancy during LA was 
greater than the probability of other modern methods of contraception.

In Indonesia the percentage of women in the LA period who take another modern contraceptive is $3.8 \%$ for the pill and $10.1 \%$ for the injection. ${ }^{7}$ This appears to be over-protective. Adamchak and Mbizyo ${ }^{8}$ stated that the introduction of contraceptives early in the postpartum period had virtually no demographic impact, and a considerable proportion of the potential effect of contraceptive practice would be wasted.

There are several factors that might affect the duration of the LA period such as the duration of full/exclusive breastfeeding, the frequency of suckling, the average duration of a suckling episode, time of introduction of supplementary food, the practice and type of pre lacteal food, the practice of breastfeeding within the first hour of birth, rooming in, age of mother, parity, the mother's nutritional status, educational and socioeconomic status. ${ }^{9 \cdot 15}$

This study objectives are to describe the pattern of breastfeeding among mothers who initially breastfeed their child, and to estimate the relationship between breastfeeding pattern and the time of resumption of menses.

\section{METHODS}

\section{Research methodology and subjects}

This study involved a cohort to diminish the recall bias and to avoid the ambiguity of time sequence relationship. To enable us to observe most of the events of interest, a long time follow-up (at least 9 months) was needed, however resources and time were limited. Therefore the follow-up took only six months and based on monthly follow-up. By this six month study it was expected to observe more than half of the events of interest (the resumption of menses) to occur.

All women who were at 34 or more week of pregnancy, attended the antenatal clinic (ANC), and intended to deliver at the Puskesmas which provided delivery service were asked to participate in this study. Volunteer mothers who intended to breastfeed and agreed to long term follow-up on a monthly basis, and who met the inclusion criteria were interviewed face-to-face. The second interview was conducted immediately at the Puskesmas in the first 72 hours after delivery before discharged. The midwife had promoted the breastfeeding information to the mothers before discharged and then reminded them to come for the next interview at the out patient clinic at the Puskesmas along with her child in the next month. The midwife always reminded the mothers to come to the out patient clinic for the next interview in every visit until six time visits.

\section{Inclusion criteria}

The inclusion criteria for subjects were: women who intended to breastfeed their children at least six months, aged $16-39$ years at the time of delivery, had no previous history of infertility and no gynecologic abnormality, had a vaginal delivery at term, and had a healthy child whose birth weight was at least 2500 grams. In addition, they should deliver in the puskesmas, agree to use either condom or intra uterine device (IUD) for contraceptive purpose during the study period and were accessible for follow-up.

\section{Exclusion criteria}

The exclusion criteria for this study was: the mother intented to use hormonal contraception before the resumption of menses.

\section{Discontinuation criteria}

A woman engaged in this study was excluded in the following circumstances: serious illness or death of the mother and/or infant, non attendance at follow-up interviews for the first three or more months consecutively, used hormonal contraception (pills, injection, or implant) before the resumption of menses, had vaginal bleeding for more than fifty six days since delivery, pregnancy which was confirmed by biochemical examination, and lochia persisted for more than 40 days.

\section{Study end points}

The occurrence of an episode of vaginal bleeding or spotting after 56 days post-partum regardless the mother had or not perceived to have a normal menstruation.

\section{Sampling}

A cluster sampling procedure was used to select the subjects. Two out of the five municipalities in Jakarta City were selected as study areas, and then 13 Puskesmas which provided delivery service and had 
the highest number of deliveries (at least 50 deliveries per month) were then selected from the areas. The collecting of respondents was ended when the sample size needed was fulfilled. The exposure group was fully/exclusively breastfeeding mothers, whereas the unexposed group was the mother who were not fully/exclusively breastfed their child.

\section{Sample size}

The total number of subjects required is dependent on the information needed about the study outcomes (the time of resumption of menses). ${ }^{16,17}$ The study design was a single cohort. The follow-up time varied for each patients, the exact time until the event of outcome for subjects who failed to come at follow-up couldn't be estimated, and the time to resumption of menses might not be normally distributed. Therefore, estimating sample size by comparing "survival time" in groups is needed. The sample size was determined by using the POWER program. ${ }^{17}$

The estimated sample size required for each group was 117 subjects. This sample size is needed, if the study is to detect a difference of eight weeks in the median duration of LA between two equal sized groups by using two-sided significance tests at the $5 \%$ probability level with statistical power of $80 \%$, accrual time 3 months, and follow-ups at 3, 4, 5, and 6 months.

The prevalence of full and partial breastfeeding changes over month. From a previous study, in the first month the prevalence of fully breastfeeding was around $77 \%$ and decreased along with time to approximately $25 \%$ in the first six months and didn't decrease anymore thereafter. Therefore, 500 subjects should be enrolled to provide 117 subjects in the full breastfeeding group in a 6-month study. However, when 500 subjects are used, there is a possibility that unequal sized groups will be achieved. The power estimation for unequal sample sizes would then be performed, using the Lachin's equation. ${ }^{18}$

\section{Data management}

A field supervisor visited and collected the data from the Puskesmas every month. Rechecking and coding data were carried out in the field. The field supervisor ascertained whether the interviewer made a mistake in filling in the questionnaire, and if so a re-interview was organized.

\section{Data collection and coding}

The data was collected by means of questionnaire and by face-to-face interviews. Interviews were conducted by the trained midwives of the Puskesmas. All interviews (eight times) except the second interview could be conducted either in the public health centre or at home. If a mother had missed an appointment at the out patient clinic, a midwife visited her at her home. The midwife then persuaded her to continue in the study after the interview ended.

\section{Data analysis}

The number of respondents who were still in the study, failed to come at follow-up (excluded), or got the resumption of menses (an event) were reported monthly by using a life table analysis. The subjects were divided into two groups: the full/exclusive breastfeeding up to three months and more than three months after birth. This study recorded serial measurements of the same variables on the same individual at several points in time (six times followup visits). The variables were the suckling frequency and the duration of suckling episode. Such data were analyzed by calculating the means and standard deviations (SD). The Kaplan-Meier life table method was used to determine the median time to the first menses on each independent variable, with a women being excluded from the life table when lost to follow-up.

This method was used since the follow-up time of respondents varied for each patient and the exact follow-up time of subjects who were lost to follow-up couldn't be estimated.

The relationship between the time of resumption of menses and several selected variables of breastfeeding patterns such as, the duration of suckling episode, the frequency of daily suckling, the duration of full/ exclusive breastfeeding, the time to the first breastfeeding, practice of pre lacteal food, and type of pre lacteal food were analyzed using the Log rank test.

\section{RESULTS}

Among the 600 mothers who agreed to participate in this study, 559 mothers were eligible but during the study 64 respondents were excluded for the following reasons. Thirty respondents used hormonal contraception within the first 56 days after delivery $(27$ respondents 
used the hormonal injection, and three respondents used the combined pill of contraception), seven respondents were bleeding for more than 56 days following delivery, and 27 respondents were lost to follow-up.

The number of respondents in the study at the first month of follow-up was 495 , and then decreased to 489 in the second month, since six of the respondents had resumed their menses between the $56^{\text {th }}$ and $60^{\text {th }}$ days. The number of respondents included in the follow-up study decreased with time. There were 200 respondents still in the study by the end of the six months (see Table 1).

Table 1. Number of respondents at the start of each time interval and number of withdrawal and events

\begin{tabular}{cccc}
\hline $\begin{array}{c}\text { Time interval } \\
\text { after delivery } \\
\text { (days) }\end{array}$ & $\begin{array}{c}\text { Number of } \\
\text { subjects at } \\
\text { the start of } \\
\text { time interval }\end{array}$ & $\begin{array}{c}\text { Number of } \\
\text { withdrawals } \\
\text { during time } \\
\text { interval }\end{array}$ & $\begin{array}{c}\text { Number } \\
\text { with retum } \\
\text { of menses }\end{array}$ \\
\hline $00-29$ & 495 & 0 & 0 \\
$30-59$ & 495 & 0 & 6 \\
$60-89$ & 489 & 5 & 86 \\
$90-119$ & 398 & 14 & 59 \\
$120-149$ & 325 & 14 & 42 \\
$150-179$ & 269 & 40 & 29 \\
$180-209$ & 200 & 186 & 14 \\
\hline
\end{tabular}

\section{The pattern of infant feeding}

The feeding practices reported were the pattern of infant feeding within the first three days after delivery and after the type of infant feeding, and the timing of introduction of different types of supplementary food.

\section{The patterns of feeding within the first three days after delivery}

Breastfeeding characteristics in the first three days after delivery included the time to the initial breastfeeding after birth, the practice and type of pre-lacteal feeding, and the practice of discarding colostrum. All of the infants received breast milk in the first 36 hours after delivery, and among them $88.5 \%$ received breast milk in the first hour after delivery.

The proportion of infants who received pre lacteal food was $13.1 \%$. Among those infants who received pre lacteal food, half of them received water. Others received pre lacteal feeding containing calories such as: sugar containing liquid, honey and infant formula. Infant formula was the second most popular prelacteal food type and was given to $41.5 \%$ of infants in the study. The practice of discarding colostrum in this study was relatively low (see Table 2). Referring to the practice of the first breastfeeding, it can be concluded that most of the respondents practiced giving colostrum to the infant in the first hour after birth. However, this study did not measure the quantity of the pre lacteal food.

Table 2. Patterns of infant feeding during the first three days after delivery

\begin{tabular}{|c|c|c|}
\hline Type of feeding & Frequency & Percent \\
\hline & $\cdot$ & \\
\hline \multicolumn{3}{|l|}{$\begin{array}{l}\text { Breastfed within the first hour } \\
\text { of delivery }\end{array}$} \\
\hline Yes & 438 & 88.5 \\
\hline No & 57 & 11.5 \\
\hline Total & 495 & 100.0 \\
\hline \multicolumn{3}{|l|}{$\begin{array}{l}\text { Time to the first breastfeed in } \\
\text { hours }\end{array}$} \\
\hline $02-05$ hours & 30 & 52.6 \\
\hline $06-11$ hours & 21 & 36.8 \\
\hline $12-36$ hours & 6 & 10.5 \\
\hline Total & 57 & 100.0 \\
\hline Infant received pre-lacteal food & & \\
\hline Yes & 65 & 13.1 \\
\hline No & 430 & 86.9 \\
\hline Total & 495 & 100.0 \\
\hline \multicolumn{3}{|l|}{ Type of pre-lacteal food } \\
\hline Plain water & 33 & 50.8 \\
\hline Sugar containing liquid & 4 & 6.2 \\
\hline Honey & 1 & 1.5 \\
\hline Infant Formula & 27 & 41.5 \\
\hline Total & 65 & 100.0 \\
\hline \multicolumn{3}{|l|}{ Infant received colostrum } \\
\hline Yes & 488 & 98.6 \\
\hline No & 7 & 1.4 \\
\hline Total & 495 & 100.0 \\
\hline
\end{tabular}

\section{Infant feeding practices during the first six months of life}

The percentage of the respondents who initiated breastfeeding in the first month was found to be $100 \%$, but the proportion of respomdents continuing to breastfeed gradually decreased to $99.1 \%$ in the six months after birth. 
Infants were generally breastfed on demand during the day as well as at night. The proportion of respondents who breastfed their infant on demand in the first month was $98 \%$, and only a few of them breastfed their infant on schedule. Night feeding was very common in this study. Almost all of the respondents breastfed their infants at night.

The average suckling frequency was determined, by asking the respondents how many times she breastfed her child for the day prior to her visit to the clinic. The average suckling frequency started slightly to decrease from the $6^{\text {rd }}$ months after delivery (see Figure 1). In this study, the respondent was asked to recall the duration of each suckling episode at the day prior to coming to the clinic. In the first three month after delivery the mean duration of suckling episodes was 16.7 minutes and ranged between 5 minutes to more than 30 minutes per episodes. By the fourth month after delivery the mean and the range of suckling duration decreased to 14 minutes/episode and from 5 to 20 minutes, and by the sixth month after delivery, the mean suckling duration was 13.0 minutes/ episode (see Figure 2). Although supplementary food is not recommended until an infant reaches four months of age, it was introduced much earlier. The proportion of infants receiving supplementary food increased rapidly with time. Only $13 \%$ had already received supplementary food in the first two months of age, and this gradually increased up to $86 \%$ by six months of age. Almost 50\% of infants had received some supplementary food in the first four months of life. Therefore, the proportion of the respondents who were full breastfeeding in the first four months was $50 \%$, and then decreased to less than $15 \%$ in the first sixth months after delivery.

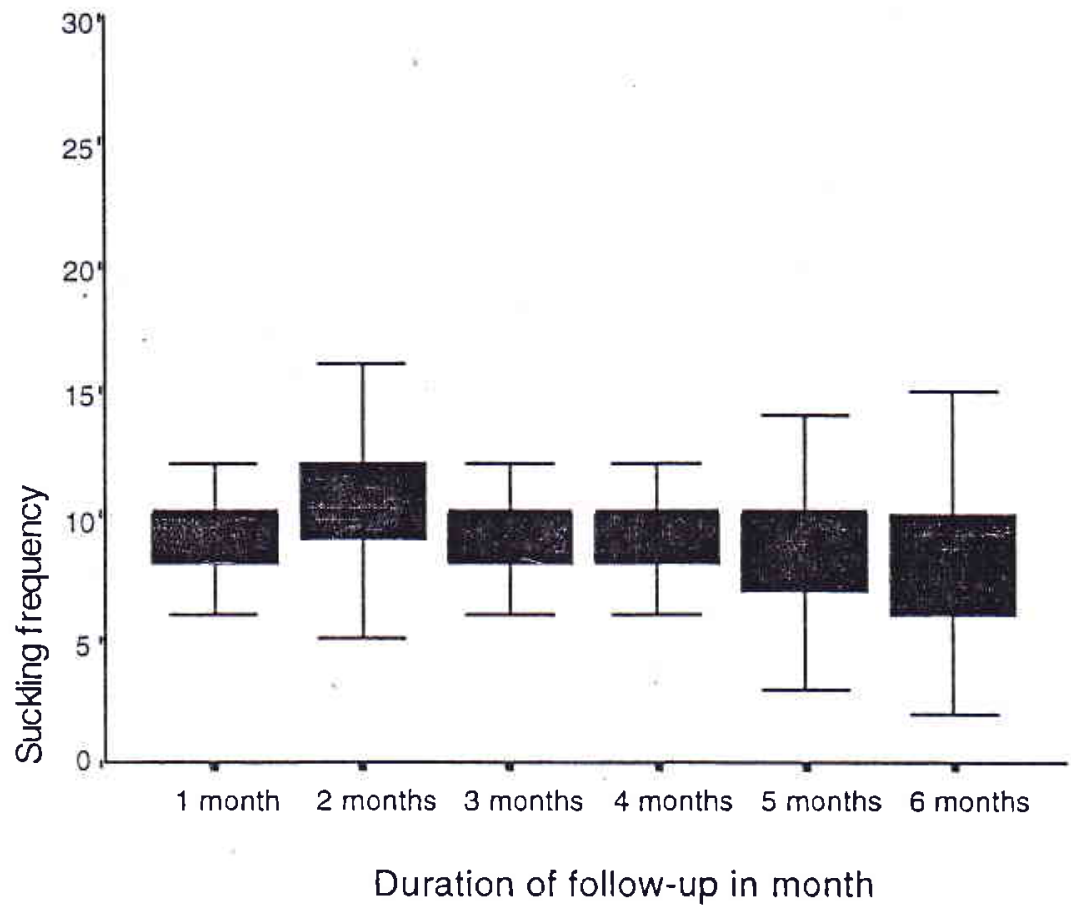

Figure I. The mean suckling frequency by duration of follow-up in months after delivery

\footnotetext{
" On schedule is the-practice of breastfeeding every two hours or eight times a day
} 


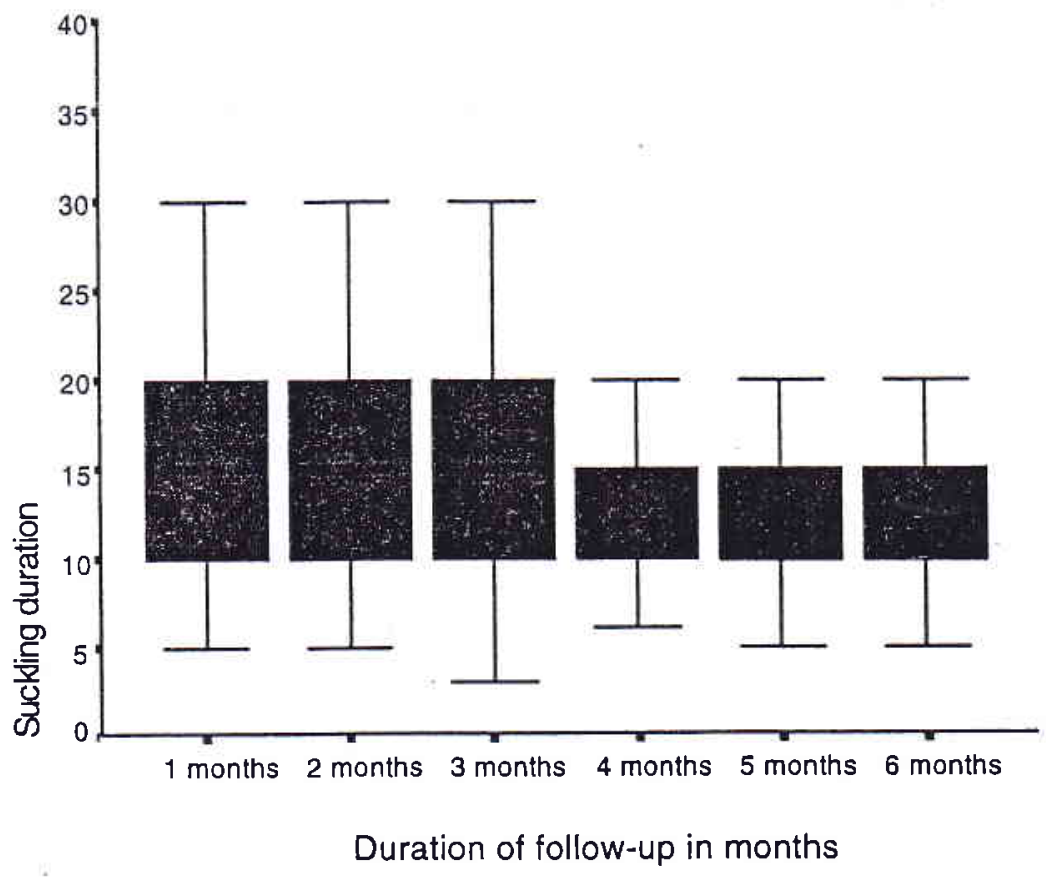

Figure 2. The mean suckling duration by duration of follow-up in months after delivery

The practice of using a pacifier was relatively constant in the first two months after delivery and then slightly decreased at the third and the fourth month, but sharply decreased by half in the fifth month. In the first months after birth the percentage of infants using a pacifier was 14.8 and this decreased with age to $7.7 \%$ in the first six months (see Figure 3).

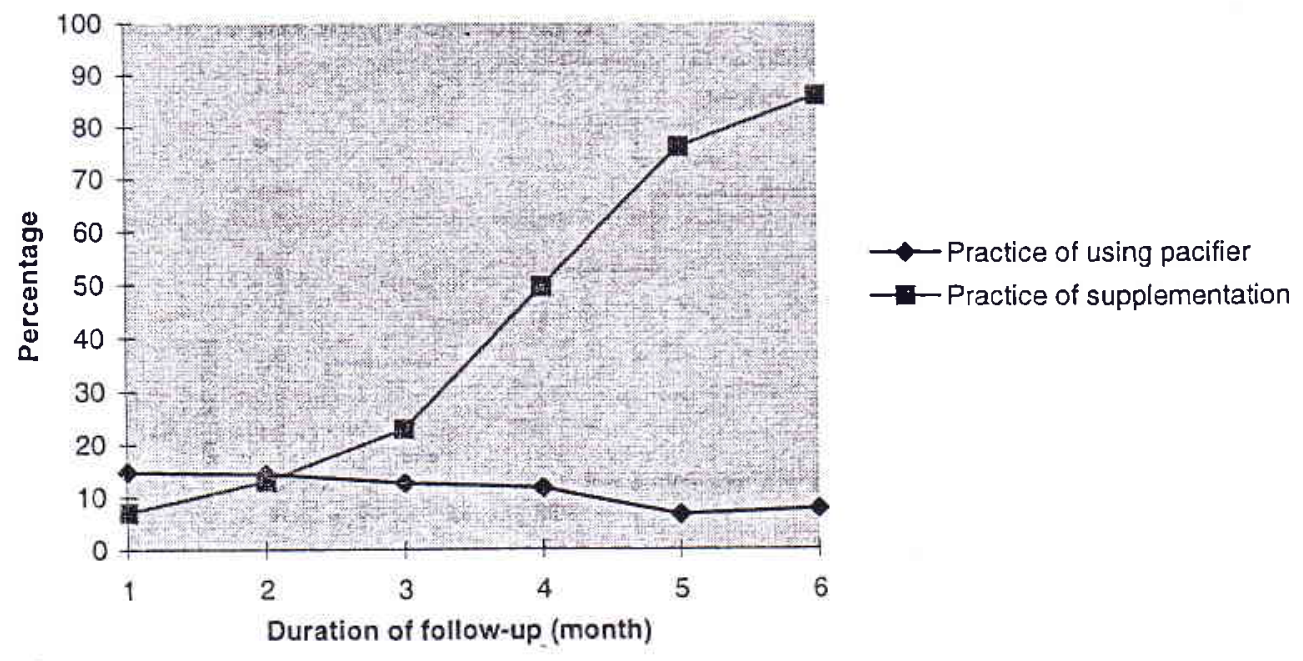

Figure 3. Percentage of breastfeeding mothers who introduced supplementary food or pacifier to their infants at different age (in months) 
In Figure 4 the percentage of each type of supplementary foods that the infant received is presented monthly from the time of discharge from the Puskesmas to the sixth month after delivery. In this study the infants in the first two months were given many types of supplementary foods such as solid food, ${ }^{* *}$ milk other than breast milk and liquids. The proportion of mashed rice or steamed rice, fruits, and milk porridge increased with time but banana, infant formula and condensed milk decreased with time. Milk porridge was preferred at the $3^{\text {rd }}$ month after delivery, and increased to more than $60 \%$ in the $4^{\text {th }}$ month after delivery. Banana was the most popular supplementary food in the first month of life, followed by infant formula. The use of milk porridge and fruits increased from $8.6 \%$ and $2.9 \%$ in the first month to 60.5 and $59.2 \%$, respectively in the sixth month.

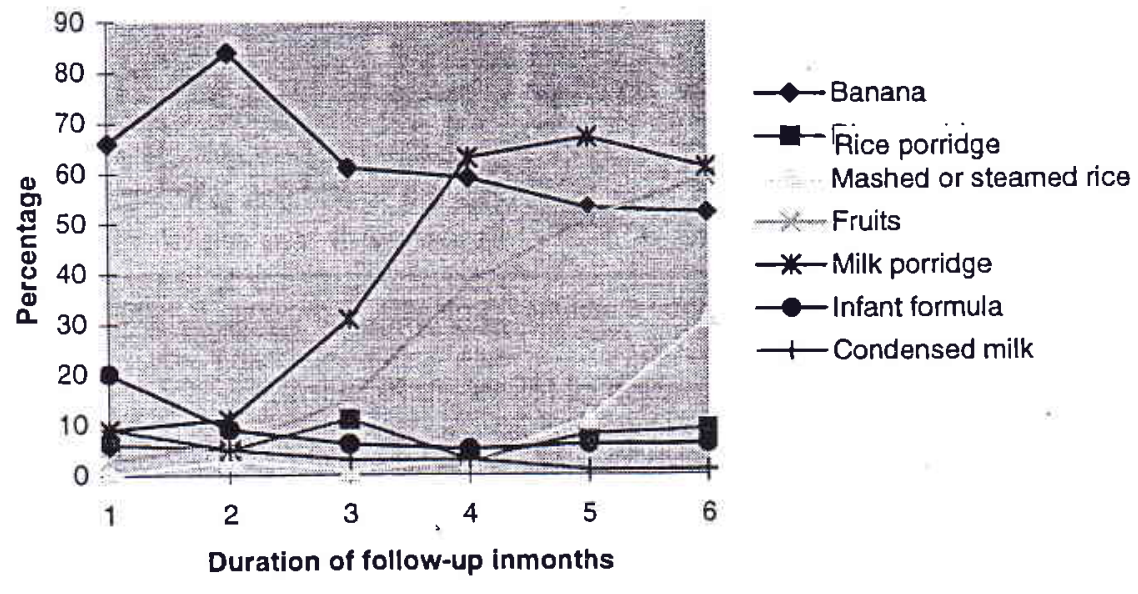

Figure 4. Percentage of infant receiving supplementary foods and the type of supplementary food by months after delivery

The median time to resumption of menses and their determinants

The association between the median time of the resumption of menses and breastfeeding pattems is shown in Table 5. Almost $20 \%$ of the respondents resumed their menses by the $90^{\text {th }}$ day after delivery, $30 \%$ by the $120^{\text {th }}$ day, and $40 \%$ by the $150^{\text {th }}$ day after delivery. Almost $60 \%$ of the respondents resumed their menses by the end of the study (see Figure 5).

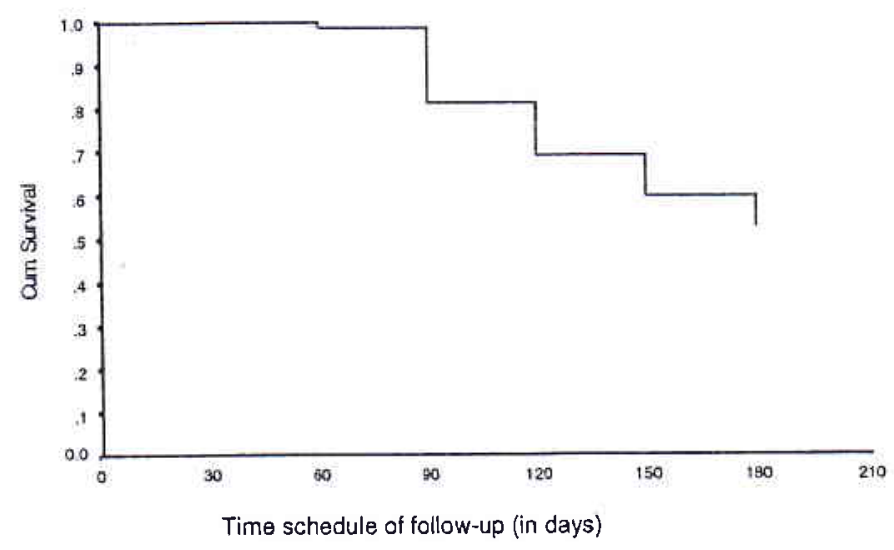

Figure 5. Cumulative survival estimate of the proportion of amenorrheic breastfeeding mother at several follow-ups (in days after delivery)

\footnotetext{
"Solid food is any solid food such as rice porridge, steamed rice, and banana
} 


\section{The median time to the resumption of menses and infant feeding characteristics}

There were six feeding characteristics analysed to assess their effect on the median time to resumption of menses. Those characteristics were the duration of full breastfeeding, the average duration of suckling episode, the average suckling frequency, the practice of breastfeeding within the first hour after-birth, the practice of giving pre lacteal food, and the practice of discarding colostrum. For this analysis, some of the breastfeeding characteristics were grouped into two categorises such as: the duration of full breastfeeding, the average duration of suckling episode, and the average frequency of suckling/day. The duration of full/exclusive breastfeeding ranged from 0 to 6 months and was categorised into two groups ie. full/exclusive breastfeeding for less than four months and the full breastfeeding for four or more months. The average suckling duration ranged from 7.5 to 30 minutes/episode, and was categorised into two groups, ie. suckling duration up to 20 minutes and suckling duration more than 20 minutes. Likewise, the average suckling frequency was categorised into two groups ie. suckling frequency up to six times and suckling frequency more than six times per day.
The cumulative survival estimate of the resumption of menses between mothers who were full breastfeeding for less than four months and mothers who were full breastfeeding for four months or more are presented in Figure 6. The estimate for the number of women with the resumption of menses among those mothers who were full breastfeeding for less than four months started to increase at the $57^{\text {th }}$ day, whereas in those mothers who were full breastfeeding for four or more months, the number of women with the resumption of menses started to increase at the $120^{\text {th }}$ day. The cumulative survival of mothers who were full breastfeeding for less than four months and who were full breastfeeding for four or more months by the end of this study were $39 \%$ and $64 \%$, respectively.

The number of respondents who were lost to followup or had the resumption of menses between mothers who practiced full breastfeeding for less than four months and for four months or more was presented in Table 3. Six of the respondents who practiced full breastfeeding less than four months had the resumption of menses at the $60^{\text {th }}$ day after delivery, whereas there were no respondents who practiced full breastfeeding for four or more months had the resumption of menses at the $120^{\text {th }}$ day after delivery (Figure 6).

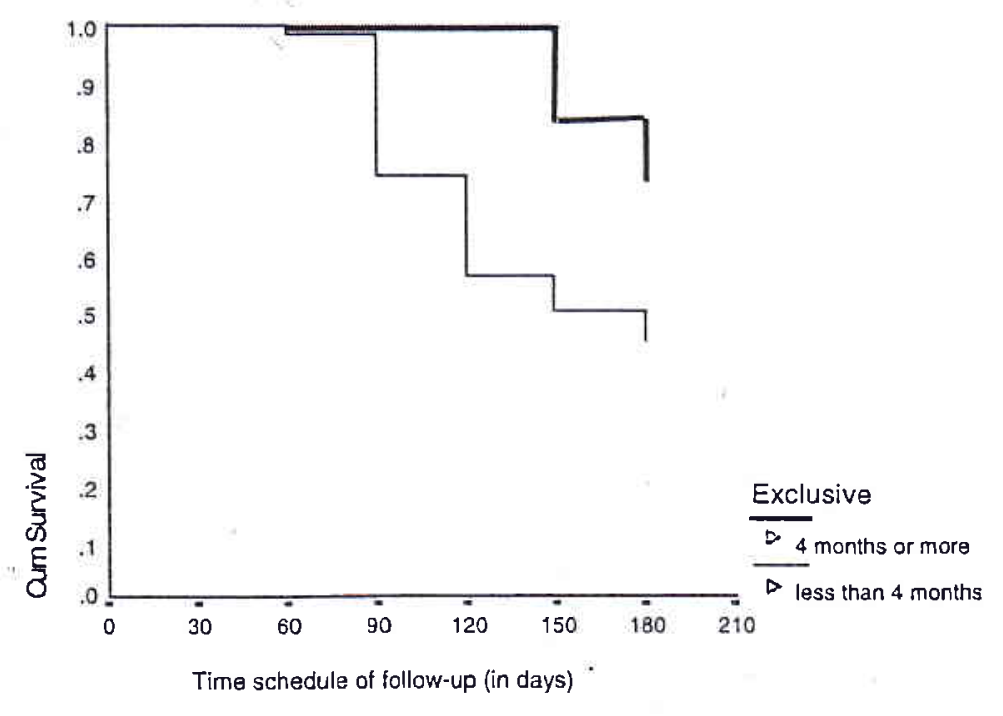

Figure 6. Cumulative survival estimate of the proportion of amenorrheic women at several follow-ups (in days after delivery) 
In the first three months of follow-up the cumulative survival estimate of the number of amenorrhoeic women in breastfeeding mothers who suckled their infant for up to six times per day and mothers who suckled their infant for more than six times per day was approximately equal. However, in the first four months, the estimate for the number of women with the resumption of menses among those mothers who suckled their infant up to six times per day decreased more sharply than for those mothers who suckled their infant more than six times per day. Almost 50\% of the respondents who suckled more than 6 times per day had not resumed their menses by the end of the study, whereas only $30 \%$ of the respondents who suckled up to six time per day had not resumed their menses by the end of the study (180 days) (Figure 7).

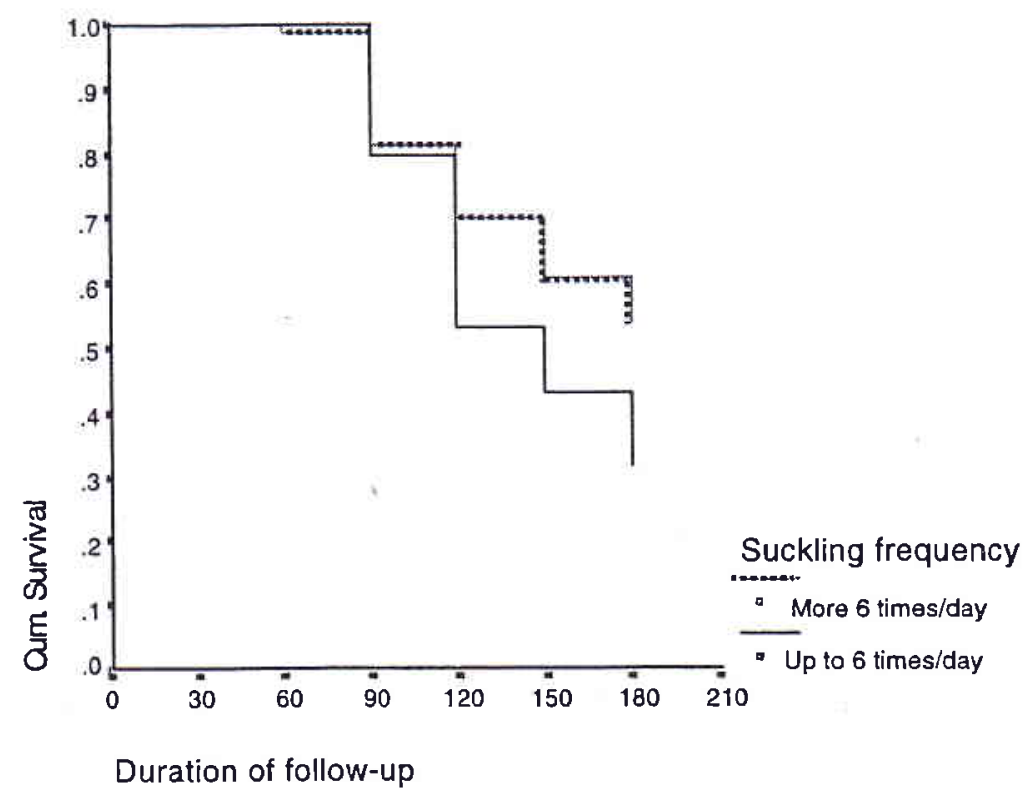

Figure 7. Cumulative survival estimate of the proportion of amenorrheic women at several follow-ups (in days after delivery)

Table 3. presents the association between the median time to the resumption of menses and the infant feeding patterns. The longer the duration of full breastfeeding, the longer was the median time of the resumption of menses. There was a statistically significant difference in the median time to the resumption of menses between mothers who were full breastfeeding for less than four months compared with mothers who were full breastfeeding for four or more months.
The result of the association between the median time to the resumption of menses and the remaining infant feeding patterns are reported in Table 3. For the remaining infant feeding patterns (between the variables), there was no significant difference in the median time to resumption of menses. For some variables of the infant feeding patterns, the median time to the resumption of menses was not able to be calculated. 
Table 3. The median time to resumption of menses by infant feeding patterns

\begin{tabular}{|c|c|c|c|c|c|c|}
\hline Feeding patterns & \multicolumn{2}{|c|}{$\begin{array}{l}\text { Time to resumption } \\
\text { of menses in days }\end{array}$} & Number & $\begin{array}{l}\text { Number } \\
\text { Events }\end{array}$ & $\begin{array}{l}\text { Percent } \\
\text { Censored }\end{array}$ & Log. rank \\
\hline Duration of full breastfeeding & & & & & & \\
\hline Less than 4 months & 149 & $121-177$ & 350 & 193 & 45 & \\
\hline $\begin{array}{l}\text { Up to Up to } 3 \text { mothsUp to } 3 \text { mothsUp } \\
\text { to } 3 \text { moths } 4 \text { months or more }\end{array}$ & 199 & $186-212$ & 145 & 43 & 70 & 0.0000 \\
\hline Suckling duration & 186 & $175-197$ & 415 & 197 & 52 & \\
\hline Up to 20 minutes & 180 & $164-196$ & 80 & 39 & 51 & 0.5701 \\
\hline \multicolumn{7}{|l|}{ More 20 minutes } \\
\hline Suckling frequency & 125 & $90-160$ & 25 & 16 & 36 & \\
\hline Up to 6 times/day & 191 & $181-201$ & 470 & 220 & 53 & 0.0224 \\
\hline More than 6 times/day & & & & & & \\
\hline Breastfed less $1 \mathrm{hr}$ after birth & 184 & $175-193$ & 438 & 212 & 51 & \\
\hline YesYesYesYesYes & NA & NA & 57 & 24 & 57 & 0.5650 \\
\hline \multicolumn{7}{|l|}{ No } \\
\hline Received pre lacteal feeding & 179 & 179 & 65 & 32 & 50 & \\
\hline YesYesYesYesYes & 186 & $177-195$ & 430 & 204 & 52 & 0.5563 \\
\hline No & & & & & & \\
\hline Received colostrum & 184 & $136-200$ & 488 & 235 & 51 & \\
\hline YesYesYesYesYes & NA & NA & 7 & 1 & 85 & 0.1760 \\
\hline No & & & & & & \\
\hline
\end{tabular}

\section{DISCUSSION}

Many studies have been conducted overseas to assess the relationship between the resumption of menses and the breastfeeding pattern among full breastfeeding and non breastfeeding women. The main aim of these previous studies was to find out the effectiveness or the possibility of using breastfeeding as a contraceptive method known as the Lactational Amenorrhoea Method (LAM). This study was primarily conducted to assess the relationship between the time of the resumption of menses and the various variables of breastfeeding patterns, in mothers who were full breastfeeding for less than four months and for four months or more. Bearing this in mind, we discuss the results of this study by comparing them with the results of previous studies. The breastfeeding pattern and the survival estimate of the time of resumption of menses and the factors affecting it are discussed. Finally, based on the above information, the appropriate time for the introduction of modern methods of contraception can be determined.

\section{The patterns of breastfeeding}

As in other developing countries, the practice of breastfeeding in Indonesia is common but relatively longer compared with those countries. This study found that over all the breastfeeding patterns were better than the results of previous study. The percentage of respondent who initiated breastfeeding, was $100 \%$ in the first month after birth and was relatively constant $(99 \%)$ in the first six months after delivery. The results of this study, however, only reflected the percentage of respondents who had intended to breastfeed and had received breastfeeding information. Therefore, this results could not be generalised to all breastfeeding mothers.

Breastfeeding the infants immediately or within 30 minutes to one hour after birth has been recommended by the WHO breastfeeding programs and the National Breastfeeding Program. However, many previous studies found that breastfeeding immediately after delivery was uncommon. There were many reasons 
addressed, namely: the breast milk had not come through yet, or the mothers were tired after delivery. This study found a significant high number of respondents who introduced breastfeeding within 60 minutes of birth $(88.5 \%)$. More than $10 \%$ of the respondents delayed the practice of breastfeeding. This might be caused by oxytocin given to a number of the respondents during delivery which could delay the onset of breast milk production.

The delay of the introduction of breast milk or breastfeeding in the first hour after delivery, can lead to the introduction of pre lacteal feeding. If the mother delay breastfeeding, the infant will be hungry and crying. If so, the mother or the family tend to introduce pre lacteal feeding earlier. The small number of mothers who practised giving pre lacteal food in this study might be due to the delay in the breast milk production. However, compared to the results of previous studies in which the practice of giving pre lacteal feeding was very common, the percentage of mothers practicing pre lacteal feeding in this study was very low.

The practice of discarding colostrum was not only common in many areas in Indonesia, but also in many other developing countries. Budi Utomo stated a number of reasons for discarding colostrum, namely: colostrum was considered stale, dirty and "watery", and to have bad or bitter taste. ${ }^{19}$ In this study the percentage of respondents who discarded their colostrum, however, was very small, only $1.4 \%$. There are some reasons which can explain this figure, such as: breastfeeding had been promoted to the mothers during the pregnancy, or the health provider did not allow the introduction of pre lacteal food. In this study, the doctors, nurses and midwives were asked to persuade the mothers to give colostrum to their infants and were also asked not to provide infant formula in their Puskesmas.

The practice of breastfeeding at night was common in many parts of Indonesia and also most of the infants were breastfed on demand. This study's findings confirmed the previous study results. The percentage of respondents practising the use of a pacifier, however, was considerably high, especially within the first month of age.

The suckling frequency is related to the volume of breast milk, the duration of full breastfeeding, the time of the resumption of menses, and the time of resumption of ovulation. The more the suckling frequency, the higher the stimulation for milk production, and the longer the resumption of menses is. The minimum average of suckling frequency which had contraceptive effect varied from one study to another. One study reported that 5 times suckling day and night had a contraceptive effect, but others found 6 times suckling per day was needed. In this study, the average suckling frequency was more than 6 times per day, so the minimum suckling frequency for having contraceptive effect was achieved. The number of respondents who breastfed less than 6 times/day was very small, and there might not be enough variance to find out the contraceptive effect between these categories.

This study showed a reversal findings; the older the infants the less the suckling frequency. The decrease in suckling frequency with time was reasonable, since the older the infant, the more the supplementary food was received, and then the less the frequency of suckling. By the same reason, the decrease in the average suckling duration with time could be explained.

The supplementary food is introduced very early in infancy in Indonesia. This study result confirmed the previous study results 911,20 in which $13 \%$ of the infants received supplementary feeding in the first month, and the supplementary feeding was gradually increased with time. Almost $50 \%$ of the infants already received supplementation in the first four months of age. The reason for introducing supplementary feeding in the first months of age was: breast milk did not come out. Further, in the older infant age the reasons were: the breast milk volume was decreased, so the mother felt that breastfeeding was not enough to nourish the infant, or the infant refused to suckle. Banana was the most popular in the first month of age and followed by infant formula.

This study found that the prevalence of full breastfeeding was higher than the previous study's results. In this study more than $90 \%$ of the mothers were full breastfeeding in the first month after delivery, and this was declined with time to $50 \%$ in the first four months of age, and then decreased to less than $13 \%$ in the first six months after birth. This study also found that the median of the duration of full breastfeeding was longer (3.0 months) compared to the previous study's result. Again, the high prevalence of 
full breastfeeding and the long duration of full breastfeeding was due to the inclusion criteria in this study.

\section{The time of resumption of menses and their potential risk factors}

The association between the median time of the resumption of menses and the patterns of breastfeeding have been conducted in many countries and the results are different from country to country, and from one study to another study. The difference in study designs, and in operational definition of the first menses, full or exclusive breastfeeding, and supplementation could cause these discrepancies. In this study, the term of full breastfeeding was use instead of exclusive or predominant breastfeeding, and the first menses was defined as any vaginal bleeding that occurred 56 days after delivery.

The time of the first resumption of menses was occurred within the $57^{\text {th }}$ and $60^{\text {th }}$ day among mothers who were full breastfeeding for less than four months, and at the $120^{\text {th }}$ day among mothers who were full breastfeeding for four months or more. This finding confirmed the previous study's result. The time of the resumption of menses in those women who breastfed in Indonesia ranged from 5 to 9.5 months (150-285 days) and this was longer compared with non breastfeeding women. The longer the breastfeeding duration, the longer the time of the resumption of menses is. This study found the median duration among women who breastfed their child was 186 days (CI: 177-195 days). This result was similar to the previous study's result which was conducted in Bangkok, but was longer compared with that conducted in Egypt and Mexico. 9,11,20

The average duration of suckling episode was positively associated with the time of the resumption of menses; the longer the duration of suckling the longer the time of the resumption of menses. The practice of breastfeeding in the first hour of birth was also associated with the length of time to the resumption of menses. The practice of giving pre lacteal feeding was negatively associated with the time of the resumption of menses. The practice of giving colostrum was positively associated with the time of the resumption of menses. $9,11,20$

None of the above variables showed a significant association with the median time of the resumption of menses in this study. This discrepancy might be due to the difference in categorising the variables. The previous study compared the time of the resumption of menses among mothers who had a different number of parities, while this study did so between mothers who already had a living child and those who had not a child yet. However, the main reason was probably the high frequency of suckling in this study.

The previous study reported that the duration of full breastfeeding affected the time of the resumption of menses, ${ }^{12-14}$ and this study confirmed this conclusion. In addition, the average of suckling frequency was significantly associated with the time of the resumption of menses.

The cumulative survival between those mothers who were full breastfeeding for less than four months and who were full breastfeeding for four months or more by the end of this study were $36 \%$ and $53 \%$, respectively. The cumulative survival between those mothers who were full breastfeeding for four months or more in this study was higher compared with the result of Peres et al. ${ }^{12}$ This finding showed that $47 \%$ of the respondents who were full breastfeeding for four or more months resumed their menses in the first six months.

It might be concluded that if a mother were full breastfeeding for four or more months, the protection from pregnancy would be only $53 \%$. This means that using the full breastfeeding for four months or more as the only contraceptive method should be reconsidered, since the over all effectiveness for contraceptive protection is only $53 \%$.

However, when full breastfeeding, regardless of the full breastfeeding duration, combined with the lack of resumption of menses, and infants' age less than six months, the effectiveness for contraception protection was great; no one was pregnant during the study period. This findings was confirmed by the Bellagio consensus. $^{2}$

If the time of the first resumption of menses could be used as a proxy time to know the resumption of fertility of a woman, then it could be used to determine the time for introducing modern contraception, if child spacing was desired, since none of the respondents had become pregnant during that time. This would be useful to avoid double protection 
against pregnancy by providing modern contraception during the period of lactational amenorrhoea. The first resumption of menses can be preceded by ovulation, but it is an unovulatory resumption of menses if it happens in first six months after delivery, providing that breastfeeding is frequent, day and night. ${ }^{12,20}$ To achieve this, the definition of resumption of menses must be any vaginal bleeding occurred after the $56^{\text {th }}$ day after delivery, irrespective whether or not the mother perceived it as a resumption of menses. As soon as any vaginal bleeding occurs after the $56^{\text {th }}$ day after delivery, any modern method of contraception has to be used.

\section{CONCLUSION}

All of the respondents initiated breastfeeding in the first month and almost all of them continued to follow-up until the end of the study. The percentage of the respondents who practised breastfeeding in the first hour, gave colostrum, and practised rooming in was very high.

However, a number of the infants received pre lacteal feeding which were consisted of water and infant formula. The practice of using pacifier during the first months of delivery was high $(14.8 \%)$ and decreased with time. Supplementary food was introduced in early infancy and sharply increased with time. Banana was the most popular.

The median time of the resumption of menses was only associated with the duration of full breastfeeding and suckling frequency. At the end of this study, the cumulative time of the resumption of menses between mothers who practiced full breastfeeding for less than four months and those who practiced full breastfeeding for four or more months were $36 \%$ and $52 \%$, respectively.

\section{Recommendations}

This study recommends suggestions for policy decision maker in breastfeeding program, health or family planning provider, researchers and individual mothers who intend to use full breastfeeding as a child spacing method.

1. In order to achieve the national target on breastfeeding program, the breastfeeding promotion should be increased throughout the country and an adequate information on breastfeeding should be provided for every mother.

2. The duration of full breastfeeding should be prolonged to gain a longer time to the resumption of menses.

3. Within six months after delivery, the modern methods of contraception is suposed not to be introduced before the time of the first resumption of menses.

4. If menses was resumed, a mother should use a modern contraception method, regardless of the duration of full breastfeeding.

5. The results of this study are not entirely consistent with previous studies; some of results are confirmed by the previous studies, some are not. Therefore, more studies with a better methodology are needed, to get a valid conclusion.

\section{Acknowledgment}

This study was funded by UNFPA/WHO Special Programme for Research and Training in Reproductive Health. I would like to thank all of my colleagues from the Department of Epidemiology, Faculty of Public Health, University of Indonesia. I am grateful to Dr. Hermini, the former Chief of the Centre for Bio-medics and Human Reproductive Research, Family Planning Coordinating Board for providing the grant for this study.

\section{REFERENCES}

1. Kennedy KI, Rivera R, McNeilly AS. Consensus statement on the use of breastfeeding as a family planning method. Contraception 1989, 39(5):477-96.

2. Bellagio Consensus. Breastfeeding as a family planning method. Lancet 1988; ii:1204-5.

3. Short RV, Lewis PR, Renfree MB, Shaw G. Contraceptive effects of extended lactational amenorhoea: beyond the Bellagio Consensus. Lancet 1991; 337: 715-7.

4. Perez A and Valdes V. Santiago Breastfeeding Promotion Program: Preliminary results of an intervention study. Am J Obstel Gynecol 1991; 165: 2039-44.

5. Gross BA. Is the lactational amenorrhoea method a part of natural family planning? Biology and policy. Am J Obstet Gynecol 1991; 165:2013-4.

6. Kennedy $\mathrm{KI}$ and Visness CM. Contraceptive efficacy of lactational amenorrhoea. Lancet 1992; 339:227-30.

7. Thapa S, Kumar S, Cushing J, Kennedy K. Contraceptive use among postpartum women: Recent patterns and programmatic implications. International Family Planning Perspective 1992; 18:83-92. 